\title{
Peertechz
}

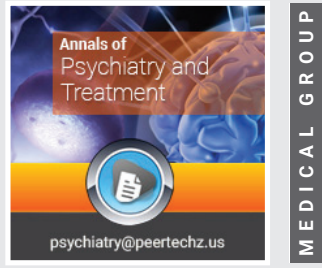

Review Article

\section{Antipsychotics and neutropoenia: An update}

\section{Luis Menéndez Rodríguez ${ }^{1 *}$, Jose Angel Méndez Sánchez ${ }^{2}$, Martin Menéndez Rodríguez ${ }^{3}$, Antonio Iglesias Pérez ${ }^{1}$, Santiago Fernández Blas ${ }^{4}$ and Maria Del Carmen Hernández Sánchez ${ }^{2}$}

'Department of Psychiatry, A Coruña University Hospital Complex (CHUAC), Oza Hospital, Xubias de Arriba, s / n - 15006 - A Coruña, Spain

2Department of Hematology, Ourense University Hospital Complex CHUO, Calle Ramón Puga Noguerol, 54 - 32005 - Ourense, Spain

${ }^{3}$ Lavadores Primary Care Health Center, Vigo Health Area, Pontevedra, 36214, Vigo, Spain

${ }^{4}$ A Cuña-Mariñamansa Primary Care Health Center, Calle Dr Peña Rey 2b CP 32004, Ourense, Spain
Received: 10 March, 2021

Accepted: 27 March, 2021

Published: 29 March, 2021

*Corresponding author: Luis Menéndez Rodríguez, Department of Psychiatry, A Coruña University Hospital Complex (CHUAC), Oza Hospital, Xubias de Arriba, s / n - 15006 - A Coruña, Spain, Tel: +34 685434553; E-mail: luis.menendez.rodriguez@sergas.es

Keywords: Agranulocytosis; Antipsychotic; Clozapine; Neutropoenia; Olanzapine

https://www.peertechzpublications.com

Check for updates

\section{Abstract}

Background and objectives: Drugs are a common reason for neutropoenia. The aim of this paper is to review the scientific evidence available in regard to cases of neutropoenia associated with the use of antipsychotics.

Methods: A bibliographic review of the last five years collected in Pubmed, Uptodate, specifications of antipsychotics and the most important Clinical Practice Guidelines, was performed.

Results: The frequency of neutropoenia associated with the use of antipsychotics and agranulocytosis is $3 \%$ and $1 \%$, respectively. Neutropoenia is most common during the first three months of treatment. Some risk factors are prior neutropoenia, age, sex, comorbidities or genetic susceptibility. Mortality is extremely rare. Most cases of neutropoenia patients are free of symptoms and they are detected in the laboratory. However, when neutropoenia is severe, the patient can even begin to present sepsis. It is recommended undertaking healthcare education for carers and patients on alarm data. The use of clozapine has a protocol for specific management and monitoring, which reduced the incidence of agranulocytosis and mortality. The incidence of neutropoenia is lower with second and third generation antipsychotics compared to clozapine.

Conclusion: The incidence of neutropoenia with antipsychotics is low. However, it is a potentially severe adverse effect. Blood work up in series needs to be performed during treatment with antipsychotics. It is possible that drugs with major antipsychotic potential such as clozapine are under used because of difficulties with their management and monitoring.

\section{Introduction}

Neutropoenia is a decrease below figures deemed normal in the peripheral blood count of neutrophils. For adults the normal neutrophil count varies between 1800 and 8100 neutrophils/ $\mathrm{mm}$ [1]. Most cases of neutropoenia in the adult are acquired and due to an increased destruction of granulocytes. Drugs are a common reason for neutropoenia of central origin. The risk of neutropoenia and other blood dyscrasias associated with multiple routinely used drugs is well known. Despite this, the use of these drugs is deemed acceptable if the clinical benefit for the patient is documented and side effects are controlled [2].

Within these drugs we have among others, chemotherapeutic agents against cancer, methamizole, anti-thyroids, sulfasalazine or trimethropin/sulfametoxazole. Psychotropic drugs such as tricyclic antidepressants, phenothiazines, carbamazepine, valproate or lamotrigine, are a common reason for neutropoenia. Within the group of antipsychotics we will 
especially highlight clozapine and olanzapine and to a much lesser extent risperidone, quetiapine or paliperidone $[1,3,4]$.

The aim of this paper is to perform an updated review of the scientific evidence available in regard to cases of neutropoenia associated with use of antipsychotics and their clinical management in psychiatry.

\section{Methods}

A bibliographic review was performed in the Pubmed database of the last five years with the terms indexed in MesH: agranuloytosis, antipsychotic, clozapine, neutropoenia, olanzapine. We analyzed the recommendations referenced on the topic in the Uptodate chapters: Drug-induced neutropoenia and agranulocytosis; Guidelines for prescribing clozapine in schizophrenia; Second generation antipsychotic medication: pharmacology, administration and side effects. We reviewed the specifications of medicines and recommendations of the Spanish Agency for Medicinal Products and Medical Devices (AEPMS). We consulted clinical practice guidelines of the British Association for Psychopharmacology, TreatmentResistant Schizophrenia: Treatment Response and Resistance in Psychosis (TRRIP) Working Group Consensus Guidelines, FDA Guidelines, NICE Guidelines, Canadian Guidelines for Pharmacotherapy in Schizophrenia in the Adult and Royal College of Psychiatrists of Australia and New Zealand Clinical Practice Guidelines for Schizophrenia.

\section{Results and discussion}

\section{Definitions, prevalence and risk factors}

Definitions: White blood cells can be classified according to the whether or not there are granules in the cytoplasm: granulocytes (neutrophils, basophils and eosinophils) and agranulocytes (lymphocytes and monocytes). Neutropoenia is defined as an absolute neutrophil count in the peripheral blood of under $1500 / \mu \mathrm{L}$. The risk of infection increases when the total neutrophil count falls below $1000 / \mu \mathrm{L}$. The term agranulocytosis is used in the case of severe neutropoenia below $500 / \mu \mathrm{L}[1]$

Prevalence: It is estimated that neutropoenia and agranulocytosis associated with antipsychotics is approximately $3 \%$ and $1 \%$, respectively, according to different series. Neutropenia is most common during the first 3 months of treatment and attains $84 \%$ of the total cases referenced in the bibliography. Approximately $75 \%$ of patients who develop mild neutropoenia will not progress to moderate or severe neutropoenia. Mortality is extremely rare, equivalent to 1 death for every 7700 patients treated [5-7].

Data from the Clozapine Pharmacovigilance Programme in the United Kingdom reveal an incidence per 100,000 people/ week of treatment of: $32 \%$ incidence in the first 18 weeks, $2.3 \%$ incidence between weeks 19 and 52 and 1.8\% incidence from week 53 onwards:

The cumulative incidence of agranulocytosis for this record is $0.78 \%$. Most cases took place during the first 18 weeks of treatment [8].
Risk factors: Various factors are identified in the literature to develop neutropoenia associated with psychotropic drugs which are [9]:

Age: more than $50 \%$ of cases occur in people aged over 50 .

Sex: more cases are identified in women than men. It is believed this is because the psychotropic drug intake of women is higher.

Patients with prior neutropoenia.

Patients with prior blood dyscrasias because of other drugs.

Coexistence of infectious mononucleosis, renal failure, autoimmune diseases, cryoglobulinaemia.

Concomitant use of ACE inhibitors or interferon.

There are populations with genetic susceptibility to neutropoenia such as Yemeni Jewish and Japanese associated with HLA B38 and HLA DRB1, respectively.

The prognosis of cases of neutropoenia associated with psychotropic drugs is worse in people aged over 60 , in counts under 100 neutrophils $/ \mu \mathrm{L}$, coexistence of septicaemia and prior morbidities which are mainly renal, cardiac or respiratory $[10,11]$.

\section{Pathogenesis of neutropoenia associated with antipsy- chotics}

It is well known that formation of the nitrenium cation by means of monooxigenase 3 in the leukocyte system is the initial step of haematological toxicity of antipsychotics. It must be recalled that most patients who begin treatment with clozapine undergo a benign leukocytosis which is due to mobilization of leukocytes from the marginal pool and bone marrow. The onset of a decrease in white blood cells would, therefore, be due to reduced production of new neutrophils. This could be mediated by an immune mechanism against neutrophils, mitochondrial oxidative stress that would lead to apoptosis of the neutrophils or direct drug toxicity on the bone marrow [2].

\section{Clinical features of neutropoenia}

Most neutropoenia patients are free of symptoms and they are detected after analytical monitoring. Oral ulcers may be a clinical manifestation, as well as non-specific symptoms such as general malaise and anorexia. On other occasions, especially when the neutropoenia is severe, the patient visits because of fever and there may even be onset of sepsis. In these cases hospital admission for intravenous antibiotic treatment is necessary. The clinician must watch out for onset of flu or odynophagia symptoms. Healthcare training for carers and patients on the alarm data is recommended. If neutropoenia is severe (below $500 / \mu \mathrm{L}$ ) and prolonged over time, the risk of bacterial infection is added to the risk of fungal infection [9].

\section{Prevention: Pre-treatment evaluation with clozapine}

There are a series of contraindicating circumstances during onset of a treatment with clozapine [12-14]. 
$\checkmark \quad$ Treatment should not be started in patients for whom periodic blood work up cannot be performed.

$\checkmark$ History of toxic or idiosyncratic agranulocytosis (except for granulocytopoenia produced by prior chemotherapy): normally an initial leukocyte count and a neutrophil count above $3500 / \mu \mathrm{L}$ and $2000 / \mu \mathrm{L}$, respectively, is required. However, the FDA reduces this to $1500 / \mu \mathrm{L}$. For benign ethnic neutropoenia (people of African or Middle East race usually have lower neutrophil counts free of infections) $>1000 / \mu \mathrm{L}$ neutrophil count and the haematologist's opinion are recommended.

$\checkmark$ Prior history of agranulocytosis because of clozapine would be a contraindication. However, if its benefits outweighs the risks then the Food and Drug Administration (FDA) deems this a relative contraindication and accepts extremely cautious management and supervision by the haematologist.

Before starting a clozapine treatment the following must be performed [12]:

$\checkmark$ Full history and medical examination that includes weight, height, muscle mass index and blood pressure.

$\checkmark$ Electrocardiogram: patients with a history of cardiopathies or trace abnormalities must be referred to a cardiologist.

$\checkmark \quad$ Full blood work up.

$\checkmark$ Determination of glycaemia and lipids is also recommended because of the high frequency of metabolic syndrome.

$\checkmark$ Some guidelines also recommend performing a pregnancy test in women of childbearing age, $\mathrm{C}$ reactive protein, troponin and completing a quantification scale of abnormal involuntary movements.

\section{Monitoring of clozapine treatment}

Monitoring the neutrophil count in patients under clozapine treatment reduced the incidence of agranulocytosis from Relative Risk (RR) 2 to RR 0.38 . Mortality fell to $0.013 \%$. In any case, some authors report that the benefits of screening can be overestimated because of the low incidence of agranulocytosis $[6,9,15]$.

There is agreement in performing $[12,14,16,17]$.

$\checkmark \quad$ weekly blood work up the first 18 weeks.

$\checkmark$ monthly blood work up whilst treatment lasts.

$\checkmark$ Blood work up 4 weeks from discontinuing clozapine treatment (as neutropoenia is reported over this period).

Currently, it is planned to reduce monitoring as of the first year of treatment because the cost-benefit ratio is doubtful in patients who did not develop prior neutropoenia [6].
There are alternatives such as capillary blood analysis that can help to improve compliance with monitoring. Moderate physical exercise should be encouraged because this leads to a raised white blood cell count. It should be borne in mind that sometimes it is not the antipsychotic that causes neutropoenia. It should also be evaluated whether other drugs the patient receives are involved, especially if there is concomitant use of methamizole or beta-lactams [2].

In the event of neutropoenia in which it is suspected that there is a causal drug, performing aspirate/bone marrow biopsy is not indicated. This is performed if the count does not recover in a reasonable time frame once the drug is suspended, with or without treatment with granulocyte colony stimulation factors (G-CSF). Or in the case of other peripheral abnormalities that lead to suspecting a non-pharmacological central cause [9].

\section{Clozapine and coronavirus disease 2019}

Some recommendations with regard to the coronavirus pandemic have recently been published [12].

The coronavirus 2019 (COVID-19) public health emergency has necessitated social isolation and staying at home. Based upon existing evidence with respect to clozapine and neutropenia, the FDA guidance and an expert consensus statement [18] suggest the following approach to using clozapine and monitoring minimum Absolute Neutrophil Count (ANC).

- For patients treated with clozapine, one may reasonably decide that obtaining mandated clozapine blood work (ANC monitoring) during the COVID-19 pandemic is impossible or entails unacceptably high risks for patients or others. As an example, patients may be in isolation or in quarantine, or at high risk for mortality if they are infected with COVID-19 while travelling to a clinic or laboratory for blood work.

- One factor that determines whether it is acceptable to waive ANC testing is duration of clozapine treatment. As an example, it is reasonable to temporarily forego testing in patients who have received the drug for at least one year and have never had an ANC <2000/ $\mu \mathrm{L}$ (or $<1500 / \mu \mathrm{L}$ if there is a history of benign ethnic neutropenia).

- Clinicians should decide whether to continue clozapine treatment in the absence of scheduled ANC monitoring in collaboration with patients and family members (or legal guardian). The risks and benefits of proceeding without ANC monitoring and the rationale for this approach should be explained.

- For patients without a current ANC, clozapine prescriptions should specify the appropriate number of pills. For many patients on long-term clozapine treatment, this may simply be an additional 30-day supply of clozapine if an ANC can be obtained the next month. However, a 60- or 90-day supply may be prudent if patients remain at high risk due to the pandemic. For patients 
newly started on clozapine, we suggest dispensing only a one- or two-week supply during the first six months of treatment, in conjunction with weekly ANC monitoring.

- Patients who develop flu-like symptoms such as fever, cough and sore throat during a period without ANC monitoring should obtain an ANC and an urgent assessment for clozapine-associated neutropenia, either in-person or remotely, depending on local protocols. Symptoms should not simply be attributed to possible COVID-19.

- Patients with flu-like symptoms may develop clozapine toxicity (e.g., sedation, myoclonus or seizures) that requires reducing the dose by up to one-half. The reduced dose should continue until the fever has abated for three days, after which the dose is then increased stepwise back to the dose used prior to onset of flu-like symptoms. Serum clozapine concentrations can help with the dose adjustments.

\section{Clinical management of neutropoenia}

For monitoring we should bear in mind the absolute neutrophil count. If this is reduced we must confirm with a second test. Performing a peripheral blood smear that reveals normal morphology of blood cells and no accompanying cytopoenia will help us rule out other pathologies that may cause neutropoenia. It is estimated that clozapine-associated neutropoenia lasts on average 12-21 days after discontinuing the drug. Table 1 summarises the most common treatment strategy recommended in each case in regard to this drug $[12,19-24]$.

Some institutions are more restrictive and recommend discontinuing clozapine if the neutrophil count is lower than $1500 / \mu \mathrm{L}[14]$

To treat neutropoenia with established drugs G-CSF (Filgastrim) can be used. However, these agents, which are outside the scope of neutropoenia caused by oncological agents, are not backed up by solid evidence. They are normally used when neutropoenia is severe. Lithium also raises leukocytes when myeloperoxidase is inhibited. It has been used to prevent neutropoenia in patients taking clozapine $[2,3,9]$.

Table 1: Recommendations for management of neutropoenia associated with clozapine.

\begin{tabular}{|c|c|c|c|}
$\begin{array}{c}\text { Stratification } \\
\text { of } \\
\text { neutropoenia }\end{array}$ & $\begin{array}{c}\text { Absolute } \\
\text { neutrophil } \\
\text { count }\end{array}$ & Recommendation \\
\hline Mild & $\begin{array}{c}1499-1000 / \\
\mu \mathrm{L}\end{array}$ & $\begin{array}{r}\text { Continue with treatment. Increase the frequency of } \\
\text { monitoring to two or three a week. }\end{array}$ \\
\hline Moderate & $999-500 / \mu \mathrm{L}$ & $\begin{array}{r}\text { Discontinue the treatment. Consult the haematologist. } \\
\text { Monitor daily until the count rises above } 1000 / \mu \mathrm{L} \text { when } \\
\text { clozapine resumption can be evaluated. }\end{array}$ \\
\hline Severe & $<500 / \mu \mathrm{L}$ & $\begin{array}{l}\text { Discontinue the treatment. Consult the haematologist. It } \\
\text { is not recommended restarting the treatment unless the } \\
\text { benefit exceeds the risks and with the haematologist's }\end{array}$ \\
\hline
\end{tabular}
agreement
The incidence of agranulocytosis with olanzapine is much less than with clozapine. Possibly because management doses are lower. Haematological toxicity of olanzapine is dosedependent. Olanzapine has a similar structure to clozapine. Therefore, it has been recommended as an alternative in patients with neutropoenia induced by clozapine. However, this safety is uncertain because olanzapine metabolites are toxic against neutrophils in vitro $[25,26]$.

In regard to the remaining second and third generation antipsychotics, the possibility of haematological abnormalities is rare. Leukocytosis and neutropoenia with risperidone has been reported in $4 \%$ of patients. Moreover, it has been reported in $2 \%$ of patients with quetiapine or paliperidone. No frequency of haematological monitoring has been recommended with these drugs [5].

- In general using clozapine in children or adolescents is not recommended because there are no safety and efficacy data. Despite this, it is observed from the short series published that neutropoenia was not more prevalent than in adults. The use of lithium has been reported as successful in children with neutropoenia because of clozapine associated with aripiprazole [2].

\section{Conclusions}

- The incidence of neutropoenia with antipsychotics is low. However, it is a potentially severe adverse effect.

- Blood work up in series should be performed when we use clozapine. This is pending a future consensus to adjust monitoring according to each patient's own risk.

- The risk of neutropoenia with second or third generation atypical antipsychotics is much lower than with clozapine. However, there is no consensus on its monitoring.

- It is important to teach patients and families about alarming clinical signs and symptoms that warn the health professional about a potential case of neutropoenia.

In light of these results we can draw the conclusion that careful management of anti-psychotic drugs is necessary. We are familiar with monitoring strategies and signs of alarm we must watch out for to avoid iatrogenic cases which in the worst case scenarios can even lead to death. Against this backdrop, recommendations in Europe are more conservative with raised requirements and controls and USA guidelines are the most flexible standards.

Once the risk-benefit of the use of antipsychotic drugs has been evaluated in each patient individually, we can state that these drugs are no more unsafe than other routinely used drugs, such as beta-lactams or methamizole. Therefore, it is possible that drugs with major antipsychotic potential such as clozapine are under used because of the difficulties in monitoring by the health professional in regard to clinical management and lack of patient compliance. In the future, it would be interesting to 
perform further pharmacotherapeutic safety studies to identify the most efficient strategy to monitor clozapine.

\section{Acknowledgements}

We thank the Ourense Official College of Physicians for assistance with translating this research paper.

\section{References}

1. Mazaira S (2008) Haematological adverse effects caused by psychiatric drugs. Vertex 19: 378-86. Link: https://bit.ly/3IWXVVc

2. Andersohn F, Konzen C, Garbe E (2007) Systematic review: Agranulocytosis induced by nonchemotherapy drugs. Ann Intern Med 146: 657-665. Link: https://bit.ly/3w1mzbL

3. Nooijen PMM, Carvalho F, Flanagan RJ (2011) Haematological toxicity of clozapine and some other drugs used in psychiatry. Hum Psychopharmacol 26: 112-119. Link: https://bit.ly/3tZw2OY

4. Vargas A, Ebner M, Gaete T (2017) Agranulocitosis secundaria a clozapina: un estudio descriptivo en pacientes chilenos Agranulocytosis secondary to clozapine: a descriptive study in Chilean patients. Rev Chil Neuro-Psiquiat 55 77-84. Link: https://bit.ly/3sssIRr

5. Second-generation antipsychotic medications: Pharmacology, administration and side effects - UpToDate [Internet]. [cited 2020 Nov 8]. Link: https://bit.ly/3fkEB30

6. Myles N, Myles H, Xia S, Large M, Kisely S, et al. (2018) Meta-analysis examining the epidemiology of clozapine-associated neutropenia. Acta Psychiatr Scand 138: 101-109. Link: https://bit.ly/3m0cl6T

7. Pons A, Undurraga J, Batalla A, Bernardo M (2012) Clozapina y agranulocitosis en España: ¿tenemos una población más segura? Seguimiento hematológico a 5 años de una cohorte de pacientes tratados con clozapina. Rev Psiquiat Salud Ment 5: 37-42. Link: https://bit.ly/3srU701

8. Munro J, O'Sullivan D, Andrews C, Arana A, Mortimer A, et al. (1999) Active monitoring of 12760 clozapine recipients in the UK and Ireland: Beyond pharmacovigilance. Br J Psychiatry 175: 576-580. Link: https://bit.ly/31/mLER

9. Coates TD (2018) Drug-induced neutropenia and agranulocytosis. 1-28. Link: https://bit.ly/3tXhTSv

10. Mena Cl, Nachar RA, Crossley NA, González-Valderrama AA (2019) Clozapineassociated neutropenia in Latin America: Incidence report of 5380 Chilean users. Int Clin Psychopharmacol 34: 257-263. Link: https://bit.ly/3cta2pG

11. Alba P (2017) Treatment-resistant schizophrenia: Neutropenia with olanzapine and clozapine, and stabilization with two depot antipsychotics. Vertex 28: 141144. Link:: https://bit.ly/3crsNtJ

12. Freudenreich O, McEvoy J (2020) Guidelines for prescribing clozapine in schizophrenia. 1-11. Link: https://bit.ly/3cnOsTI

13. Sultan RS, Olfson M, Correll CU, Duncan EJ (2017) Evaluating the effect of the changes in FDA guidelines for clozapine monitoring. J Clin Psychiatry 78 e933- e939. Link: https://bit.ly/3fiqE5v

14. AEMPS (2018) Ficha Técnica 1. Nombre Del Medicamento. 10. Link: https://bit.ly/3rsmVVI

15. Honigfeld G, Arellano F, Sethi J, Bianchini A, Schein J (1998) Reducing clozapine-related morbidity and mortality: 5 years of experience with the Clozaril National Registry. J Clin Psychiatry 59: 3-7. Link: https://bit.ly/2P3AkGx
16. Mena Cl, Nachar RA, Crossley NA, González-Valderrama AA (2019) Clozapineassociated neutropenia in Latin America: Incidence report of 5380 Chilean users. Int Clin Psychopharmacol 34: 257-263. Link: https://bit.ly/3m3jt2r

17. Barnes TRE, Drake R, Paton C, Cooper SJ, Deakin B, et al. (2020) Evidencebased guidelines for the pharmacological treatment of schizophrenia: Updated recommendations from the British Association for Psychopharmacology. J Psychopharmacol 34: 3-78. Link: https://bit.ly/39mBBz4

18. Siskind D, Honer WG, Clark S, Correll CU, Hasan A, et al. (2020) Consensus statement on the use of clozapine during the covid-19 pandemic. J Psychiatry Neurosci 45: 200061. Link: https://bit.ly/2QELEZT

19. Sultan RS, Olfson M, Correll CU, Duncan EJ (2017) Evaluating the effect of the changes in FDA guidelines for clozapine monitoring. J Clin Psychiatry 78: e933- e939. Link: https://bit.ly/31oQ4Gw

20. Gibson C, Berliner N (2014) How we evaluate and treat neutropenia in adults Blood 124: 1251-1258. Link: https://bit.ly/3suXleh

21. Psychosis and schizophrenia in adults: prevention and management. Recommendations | Psychosis and schizophrenia in adults: prevention and management | Guidance |. NICE National Institute for Health and Care Excellence. NICE. Link: https://bit.ly/3fqGuuK

22. Remington $G$, Addington D, Honer W, Ismail Z, Raedler T, et al. (2017) Guidelines for the Pharmacotherapy of Schizophrenia in Adults. Can J Psychiatry 62 604-616. Link: https://bit.ly/3w2oYTC

23. Howes OD, McCutcheon R, Agid O, De Bartolomeis A, Van Beveren NJM, et al. (2017) Treatment-Resistant Schizophrenia: Treatment Response and Resistance in Psychosis (TRRIP) Working Group Consensus Guidelines on Diagnosis and Terminology. Am J Psychiatry 174: 216-229. Link: https://bit.ly/3IXTMAw

24. Galletly C, Castle D, Dark F, Humberstone V, Jablensky A, et al. (2016) Royal Australian and New Zealand College of Psychiatrists clinical practice guidelines for the management of schizophrenia and related disorders. Aust N Z J Psychiatry 50: 410-472.

25. Ng W, Kennar R, Uetrecht J (2014) Effect of clozapine and olanzapine on neutrophil kinetics: Implications for drug-induced agranulocytosis. Chem Res Toxicol 27: 1104-1108. Link: https://bit.ly/39mIKQa

26. Malhotra K, Vu P, Wang DH, Lai H, Faziola LR (2015) Olanzapine-induced neutropenia. Ment IIIn 7: 5871. Link: https://bit.ly/3sxpRS0

\section{Discover a bigger Impact and Visibility of your article publication with}

\section{Peertechz Publications}

\section{Highlights}

* Signatory publisher of ORCID

* Signatory Publisher of DORA (San Francisco Declaration on Research Assessment)

* Articles archived in worlds' renowned service providers such as Portico, CNKI, AGRIS, TDNet, Base (Bielefeld University Library), CrossRef, Scilit, J-Gate etc.

* Journals indexed in ICMJE, SHERPA/ROMEO, Google Scholar etc.

* OAI-PMH (Open Archives Initiative Protocol for Metadata Harvesting)

* Dedicated Editorial Board for every journa

* Accurate and rapid peer-review process

* Increased citations of published articles through promotions

* Reduced timeline for article publication

Submit your articles and experience a new surge in publication services (https://www.peertechz.com/submission).

Peertechz journals wishes everlasting success in your every endeavours.

Copyright: @ 2021 Rodríguez LM, et al. This is an open-access article distributed under the terms of the Creative Commons Attribution License, which permits unrestricted use, distribution, and reproduction in any medium, provided the original author and source are credited. 